\author{
М.Я. Дымарский \\ Российский государственный педагогический университет им. А. И. Гериена / \\ Институт лингвистических исследований РАН \\ (Санкт-Петербург, Россия) \\ dym2005@list.ru
}

\title{
РАСПАД ПОДЧИНЕНИЯ И ЛЕКСИКАЛИЗАЦИЯ ПРЕДИКАТИВНОЙ СТРУКТУРЫ*
}

Рассматриваются конструкции типа (1) Он занимается черт знает чем, по отношению к которым Л.Л. Иомдиным ранее была выдвинута «гипотеза о двух синтаксических началах» (вершинах) (см. одноименный раздел в [Апресян и др. 2010]). Показано, что подобная гипотеза могла появиться только на базе постулатов, применяемых при исчислении синтаксических отношений и моделировании предложения в Синтаксически размеченном подкорпусе Национального корпуса русского языка (СинТагРус), но этим же постулатам данная гипотеза противоречит. Рассматриваемая конструкция анализируется как результат распада подчинения в исходной конструкции Черт знает, чем он занимается. Двойной зависимости формы творительного падежа чем (от знает и от занимается) нет не только в производной, но и в исходной конструкции, где глаголу знает подчинено не местоимение, а придаточное целиком. В производной же конструкции (1) наблюдается результат лексикализации бывшей главной части сложноподчиненного предложения, которая превращается в единицу, аналогичную другим бывшим главным частям со значением неопределенности (неизвестно, неведомо) и так же, как эти показатели, подчиняющую не всю придаточную часть, а лишь то, что осталось от нее после вынесения предикативного центра последней левее бывшей главной части. Подчинением эту вырожденную связь назвать нельзя: это лишь рефлекс подчинения. Основание для лексикализации заключается в том, что структура черт знает, примыкая, как в (1), к вопросительно-относительному местоимению, выражает уникальный семантико-прагматический комплекс значений,

* Работа выполнена при поддержке РФФИ, проекты №№ 18-012-00650 «Семантические категории в грамматическом строе русского языка», 17-29-09 158 «Создание корпуса официальноделовых текстов русского языка (ОДКРЯ)», 18-012-00 778 «Теоретические основания кодификации русской пунктуации». 
недоступный стандартным неопределенным местоимениям: максимальная степень неопределенности + неодобрение говорящего. При этом значение неизвестности, свойственное исходной конструкции, может быть редуцировано до нуля. Лексикализованная структура черт знает обогащает репертуар средств выражения семантической категории неопределенности.

Ключевые слова: синтаксис, сложноподчиненное предложение, синтаксические связи, распад подчинения, рефлекс подчинения, лексикализация, семантическая категория неопределенности.

0. В одной из своих работ Л.Л. Иомдин, рассматривая конструкции типа:

\section{(1) Он занимается черт знает чем,}

— выдвинул «гипотезу о двух синтаксических началах» [Апресян и др. 2010: 129141]. Идея в том, что форма Тв. п. в этой конструкции одновременно объясняется как связью занимается чем, так и связью [черт] знает, чем [он занимается], и получается, что она является дуплексивом, одновременно подчиненным двум вершинам.

Существование дуплексивов не новость для отечественной грамматической традиции, хотя чаще понятие дуплексива используют для характеристики случаев типа

(2) Красавица и умница, она всегда пользовалась успехом у мужчин,

- где приложение обнаруживает как аппозитивную связь с подлежащим (свернутое до атрибутивного предикативное отношение), так и смысловую связь со сказуемым (причинное отношение). Однако занимательность ситуации в том, что «гипотеза о двух синтаксических началах» выдвинута в рамках одной из тех синтаксических теорий, которые отличаются приверженностью к жесткому детерминизму, исключающих самоё возможность существования двух вершин в пределах одного предложения.

«В период становления и развития опытной науки в качестве базовых выступали модели, олицетворением которых явилась классическая механика. Основной особенностью этих моделей является строго однозначный характер всех связей и зависимостей, характеризующих исследуемые явления, системы и процессы. Эти модели получили название моделей жесткой детерминации», - так характеризуется жесткий детерминизм в [Сачков 2010: 631]. Этой характеристике вполне отвечают последовательно вербоцентрическая концепция предложения и типология синтаксических отношений, которая предусматривает существование в синтаксисе связей исключительно типа «хозяин - слуга», что ведет к интерпретации в качестве зависимости (причем трудно понять, чем зависимость отличается от подчинения) в том числе и связей между сказуемым («хозяин») и подлежащим («слуга»), предлогом («хозяин») и именем («слуга»), союзом («хозяин») и сказуемым придаточного предложения («слуга») и т. п., подробнее см. раздел «1.2. Синтаксические отношения» в [Апресян и др. 2010] (автор раздела Л. Л. Иомдин), 
с незначительными изменениями повторенный в «Синтаксически размеченном подкорпусе Национального корпуса русского языка» [СинТагРус]; полемику см. в [Дымарский 2013; 2014].

Между тем, если «гипотеза о двух синтаксических началах» может быть с успехом применена для объяснения таких конструкций, как приведенная выше (2), которая с успехом подтверждает, мягко говоря, условность строго вербоцентрической концепции предложения, то для случая (1) возможны как раз менее радикальные интерпретации.

1. Первая из них заключается в признании производности (1) от стандартного сложноподчиненного предложения

$$
\text { Черт знает, чем он занимается. }
$$

Л. Л. Иомдин справедливо подчеркивает различие между (1) и (3), но видит его в том, что (3) представляет собой стандартное сложноподчиненное предложение, a (1) - сложное предложение с наложением частей: первая начинается подлежащим $о н$, вторая - подлежащим черт (то есть левые границы у них не совпадают), но обе заканчиваются относительным местоимением (правые границы частей совпадают) [Указ. соч.: 133-134]. Однако представляется осмысленным и иной взгляд: (1) не является сложноподчиненным; это простое предложение, образовавшееся из (3) путем «втягивания» главной части внутрь придаточной. Причину, обусловившую этот процесс, можно видеть в том, что при этом происходит смещение смысловых акцентов и, соответственно, изменение прагматических функций предложения. Если (3) вряд ли может быть инициальной репликой диалога и, скорее всего, призвана служить ответом на вопрос «Чем он занимается?» — правда, не слишком содержательным, так как смысл такого ответа приблизительно передается как 'я не знаю [чем он занимается]', — то (1) может быть не только реактивной, но также инициальной репликой или фрагментом характеристики лица, и смысл (1) передается иначе (см. ниже 2.2).

Подобное «втягивание» главной части внутрь придаточной — характерная черта разговорного синтаксиса, нередко встречающаяся в различных вариантах, например, у Л.Н. Толстого:

...что он (Ростов. - М.Д.) так и уедет, не продав графу Голуховскому тройку саврасых, которых польский граф торговал у него и которых Ростов на пари бил, что продаст за 2 тысяячи... («Война и мир». Т. II, ч. 4).

Коммуникативные и смысловые различия между (3) и (1) отражаются в их линейно-акцентной структуре: только в (3) черт является акцентоносителем выдвинутой влево ремы = носителем фразового ударения; в (1), если исключить эмфазу на словоформе черт, акцентоносителем ремы является относительное местоимение.

Однако, при всех этих различиях, конструктивно (1) наследует конфигурацию связей в (3), где форма Тв. п. прямо зависит от глагола-сказуемого придаточной части, а зависимости ее от глагола-сказуемого главной части (знает) как раз нет: 
от знает зависит вся изъяснительная придаточная часть, являясь таким же делибератом контактного глагола, как, скажем, именная группа в словосочетании знает род его занятий. Чем - в качестве союзного слова - оказывается в фокусе этой связи, в результате чего и возникает иллюзия его зависимости от знает, которая поддерживается устойчивостью контактных рамок типа знать, что..., знать, куда..., спросить, почему..., весть, что... и т.д. (см., в частности, [Ильенко, Лёвина 2007]). Однако полагать, что имеет место прямая зависимость между знает и чем - примерно то же, что считать, будто в словосочетании рубит топором от глагола зависит окончание -ом, а от последнего, в свою очередь, - «остальное» имя. Форма чем всецело определяется зависимостью местоимения от занимается: это очевидно хотя бы из того, что точно так же выглядит и омонимичное вопросительное предложение (Чем он занимается?), являющееся исходной формой для изъяснительного придаточного вопросительной разновидности. Глаголу знать, как и любому контактному слову, подчиняющему изъяснительное придаточное, безразлично, чем «управлять»: в качестве подобных «зависимых» могут выступать любые местоимения в любых формах, в том числе местоименные наречия; это означает, что в реальности никакого управления, никакой зависимости союзного слова от контактного слова главной части нет.

Тем не менее, отвергаемая нами интерпретация возможна, если образ синтаксиса опирается на следующие постулаты: «Каждое слово предложения, кроме одного (называемого вершиной предложения), зависит от какого-то слова по одному из синтаксических отношений. Отношения связывают только отдельные слова, а не словосочетания. В случае так называемых синтаксических групп один из членов группы выступает в качестве представителя группы во внешних связях (локальной вершины группы) и подчиняет остальные члены группы» [СинТагРус; полужирный шрифт мой. - M.Д.]. Именно эти постулаты ведут к признанию союзного слова, с одной стороны, вершиной придаточного предложения (и тогда непонятно, каким образом эта вершина может зависеть от сказуемого этого же придаточного), с другой стороны - прямым зависимым контактного слова знает. Сложное предложение предстает как однолинейная непрерывная цепочка зависимостей; целостность (пусть и относительная) его предикативных компонентов исчезает; ведущий компонент его смысла - логико-смысловое отношение между предикативными частями - становится просто одним из синтаксических отношений в непрерывной цепочке; вершиной второй части (любой: подчиненной, сочиненной) становится служебный элемент, который подчиняет себе сказуемое этой части... Это не попытка дискредитировать положения оппонента путем доведения их до абсурда: это реальность синтаксической разметки в [СинТагРус]: см., в частности, примеры, в которых вершиной предложения оказывается служебное слово: http://ruscorpora.ru/syntax/uppsala/74_30.pdf, http://ruscorpora.ru/syntax/2009/81_65. pdf, http://ruscorpora.ru/syntax/2009/81_64.pdf.

Таким образом, интерпретация связей в (3), не противоречащая цитированным постулатам, создает неразрешимые противоречия; интерпретация же, опирающаяся на более традиционные синтаксические представления, во всяком случае 
от противоречий избавлена. Если опереться на вторую и исходить, напомним, из преемственности конфигурации связей между (3) и (1), то двойная зависимость формы Тв. п. исключается как для (3), так и для (1).

2. Вторая из менее радикальных, чем «гипотеза о двух синтаксических началах», интерпретаций определяется вниманием к тому, во что превращается в (1) черт знает - бывшая главная часть (3).

2.1. Хотя внешне это предикативная структура, у нее, в отличие от функционирования в составе (3), отсутствует парадигма (отмечено Л. Л. Иомдиным [Указ. соч.: 138]). Неприемлемо:

(5а) *Он занимался черт знал чем;

(5б) *Он будет заниматься черт будет знать чем;

(5б) *Он занимался бы черт бы знал чем

- и т.д. (см. также ниже примеры 7-9, 12). При функционировании в составе (3) варьирование предикативной формы тоже ограничено. Скорее, мы скажем:

(6) Черт знает, чем он занимался,

— но в более широком контексте возможен и вариант:

(6а) Один только черт знал, чем он там занимался.

Невозможность (5а-в) при возможности (6а) - важная особенность функционирования черт знает в составе (1). В свою очередь, утрата предикативной структурой способности к свободному изменению в рамках предписанного набора грамматических значений - первый признак лексикализации.

2.2. В семантическом плане устойчивая структура черт знает (будем пока называть ее так) различна в конструкциях (3) и (1). В (3) на первом плане - значение неизвестности, причем употребление структуры черт знает обусловлено стремлением выразить значение 'неизвестно никому, в том числе говорящему', ср. типичные примеры:

(7) Далее стоять тут было небезопасно - чёрт знает, что могла выкинуть там эта женщина [Василь Быков. Болото (2001)]';

(8) Возвращзаюь часа через три - черт знает, о чем писать! [Владимир Арро. Дом прибежища // «Звезда», 2002];

(9) Черт знает, где я до этого обитал, в тумане собственного испарения, что ли?.. [Владимир Арро. Там же].

Между тем в конструкции (1) значение неизвестности хотя и может сохраняться, но приглушается, говорящему не сообщаемая им информация на самом деле может быть известна. На первый же план выходит семантика неодобрения (отмечено Л. Л. Иомдиным [Указ. соч.: 140], причем в (10-11) неодобрение имитируется с целью

${ }^{1}$ Примеры с атрибуцией в квадратных скобках извлечены из Национального корпуса русского языка. 
втереться в доверие к собеседнику. Говорящий рассчитывает на то, что собеседник адекватно воспримет эту коннотацию, а тождество вкладываемых и считываемых коннотаций является важным фактором сближения позиций говорящего и слушающего. Использование Коровьевым с этой целью именно данного средства свидетельствует о полной узуальности структуры черт знает в рассматриваемой функции:

(10) Да он уж уехал, уехал! - закричал переводчик. - Он, знаете ли, уж катит! Уж он черт знает где! (М. А. Булгаков. Мастер и Маргарита);

Говорю вам, капризен как черт знает что! - зашептал Коровьев (Там же);

Более того, из (12) следует, что не сообщаемая говорящим информация может быть известна не только ему, но и адресату:

Я вот, сам знаешь, жил почти всю жизнь черт знает где черт знает с кем, - мимолетно оболгал Валера первую жену и свое в действительности теплое отношение к ней [Алексей Слаповский. Большая Книга Перемен // «Волга», 2010].

3. Отмеченная прагматико-семантическая специализация структуры черт знаem в модели (1) отличает ее от частиц-постфиксов -то, -нибудь и -либо, формирующих соответствующие серии неопределенных местоимений. Неопределенные местоимения неспособны выразить ту максимальную степень неопределенности (семантическая специфика), помноженную на неодобрение говорящего (прагматическая специфика), которые столь ясно выражаются комбинацией черт знает + отн. мест. В самом деле, замена черт знает где черт знает с кем в (12) на любое из неопределенных местоимений дает неприемлемый результат:

(12а) *Я вот, сам знаешь, жил почти всю жизнь где-то с кем-то / где-нибудь с кем-нибудь / где-либо с кем-либо.

В противном случае можно было бы объявить черт знает фразеологическим функциональным эквивалентом частицы-постфикса - но тогда неясно было бы, для чего в языке возник такой эквивалент. Такое решение обсуждается и в указ. раб. Л. Л. Иомдина (с. 131) и тоже отвергается — на том основании, что «инвентарь вложенных конструкций, обнаруживающих сходное синтаксическое поведение, $<\ldots>$ может включать в себя вполне свободные словосочетания, образованные довольно широким кругом глаголов» [Там же]. Однако в приводимых при этом примерах фигурирует не столь уж много глаголов (4, из них 3 однокоренных), а главное - круг этих лексических единиц очерчен вполне ясно: это глаголы или слова других частей речи, имеющие делиберативную валентность и поэтому способные присоединять соответствующее дополнение или изъяснительное придаточное. Речь, таким образом, идет о процессе, затрагивающем главные части сложноподчиненных предложений с изъяснительными придаточными вопросительной разновидности, в которых связь обеспечивается, как известно, или местоимениями, или другими средствами, оформляющими исходный вопрос: союзом или (при альтернативном вопросе) и частицей ли (при общем модальном вопросе). 
Справедливости ради нужно отметить, что в разговорной речи функционирует вариант местоимения что-то (иногда с продолжением с чем-то), заметно отличающийся от стандартных неопределенных местоимений выраженным акцентным выделением и значением высшей степени положительной оценки при нуле квалификативного значения:

\section{(13) Tы видела Машино новое платье? Это что-то!}

Можно предполагать, что неопределенно-положительно-оценочное что-то возникло в результате опущения последующего оценочного прилагательного (необыкновенное, удивительное, потрясающее и т. п.). Но ясно, что к выражению того семантико-прагматического значения, на котором специализируется черт знает + отн. мест., этот вариант местоимения неспособен.

Мнимая эквивалентность комплекса иерт знает + отн. мест. стандартным неопределенным местоимениям делает избыточной постановку вопроса о грамматикализации структуры черт знает в качестве строевого средства, аналогичного постфиксу неопределенности: речь может идти только о ее лексикализации. Сходный процесс коснулся и таких лексических средств выражения неопределенности, как неизвестно, неведомо, невесть, которые также исходно являются главными частями изъяснительных сложноподчиненных предложений. При этом, однако, структура черт знает обладает намного более яркой семантико-прагматической спецификой, хотя значение неодобрительности, как кажется, развивается и у названных единиц. Л.Л. Иомдин видит лексикализацию только в процессе, происходящем с выражениями этого последнего типа (кроме названных - непонятно + отн. мест., черт-те + отн. мест., не пойми + отн. мест., жаргонное $X 3$ + отн. мест.), причем, говоря, что они «превращаются в отдельные слова», но добавляя, что они приближаются, «каждое со своей скоростью, к неопределенным частицам типа -либо, -то и пр.», автор фактически признаёт их находящимися в стадии грамматикализации [Указ. соч.: 140]. С нашей точки зрения, можно говорить о лексикализации всего круга названных средств (восходящих к главной части изъяснительного сложноподчиненного предложения), если они обладают семантико-прагматической спецификой, отличающей их от суффиксальных показателей неопределенности, и только если доказано отсутствие такой специфики - о грамматикализации.

4. Вернемся к связи внутри комплекса черт знает + отн. мест. Механизм «втягивания» главной части изъяснительного сложноподчиненного предложения в придаточную часть состоит в линейно-акцентном преобразовании - перемещении фрагмента придаточного, включающего как минимум один из компонентов предикативного центра, левее главной части. Что при этом происходит?

Известно со времен А. М. Пешковского, что сложноподчиненное предложение, в отличие от сложносочиненного, не обладает признаком непроницаемости структуры. Это означает, что придаточная часть может пересекать границы главной, оказываясь в интерпозиции:

(14) Маша, если ее отпустят после обеда, приедет вовремя. 
Однако такие преобразования сомнительны, во всяком случае в рамках литературной нормы, для предложений с изъяснительными придаточными:

?Я, что вы очень заняты, знаю.

Главное же в том, что проницаемой может быть главная часть по отношению к придаточной, но не наоборот. Придаточная часть для главной непроницаема (явления ненормативной спонтанной устной речи здесь во внимание не принимаем):

(14a) *Если ее, Маша приедет вовремя, отпустят после обеда;

(14б) *Если Машу, она приедет вовремя, отпустят после обеда;

(15а) *Что вы, я знаю, очень заняты.

Причина непроницаемости придаточной части для главной представляется очевидной: только в случае целостности придаточного его подчиненность главному прочитывается без затруднений. Из (15a) видно, что нарушение этой нормы ведет к переосмыслению интерпонированной главной части в качестве вводного предложения, а союз «повисает в воздухе» и может быть осмыслен только как средство связи (15a) с каким-то другим главным предложением. Таким образом, нарушение требования целостности придаточного ведет к выходу его части, смещенной влево от главного предложения, из скопуса ${ }^{2}$ подчинения. В сфере действия подчинения в (1) остается только союзное слово. Тем самым содержание связи - делиберативное синтаксическое отношение - выхолащивается, фактически происходит распад подчинения, потому что можно знать, чем Х занимается, но нельзя знать только чем: оставленное в одиночестве местоимение не может служить содержательным ответом на вопрос, что знает $X$, и, следовательно, не реализует делиберативное отношение. Последнее лишь реконструируется путем ретроспекции к фрагменту придаточного, вынесенному влево, но это относится уже к мыслительным операциям, необходимым для понимания конструкции, а не к устройству конструкции. В грамматиках составляющих в подобных случаях используется понятие следа (trace), оставшегося от перемещенного компонента, что можно обозначить применительно к (1) так:

[Он занимается $]_{\mathrm{i}}$ (черт знает) [чем $\left.\mathrm{t}_{\mathrm{i}}\right]$.

Во что же вырождается содержательно выхолощенная подчинительная связь, на которой базировалась полипредикативная структура? Нельзя сказать, что она утрачивается полностью, иначе было бы невозможным сохранение в аналогичных конструкциях — с «втягиванием» главной части — чисто формального, не относительного подчинения:

(17) Его судят за преступление, которое он неизвестно совершил или нет (пример Л. Л. Иомдина).

Эту вырожденную связь можно было бы уподобить примыканию, поскольку местоимение сохраняет в застывшем виде ту форму (если это не местоименное

${ }^{2}$ Англ. scope - границы, рамки, пределы, сфера действия; восходит к лат. scopus. 
наречие), которую оно имело в исходной конструкции (3), и в этом смысле, как и союз или и частица ли, ничем не проявляет свою зависимость от (бывшего) контактного слова знает. Но речь может идти только о подобии в формальном смысле, так как в данном случае связь семантически выхолощена, а в случае примыкания это невозможно. Стандартное примыкание, с характерной для него определительно-обстоятельственной семантикой, представляет собой, кроме того, первичную синтаксическую связь - в том смысле, что оно не является вырожденным подчинением, оставшимся после распада полипредикативной структуры.

Важно иметь в виду, что применительно к (1) речь идет о том, что осталось на поверхностно-синтаксическом уровне от подчинительной связи между контактным словом главной части и придаточной частью, — а это, в сущности, связь (?) между бывшим контактным словом и показателем связи. Если исходить из постулатов, цитированных в п. 1, такая связь может быть. С нашей же точки зрения, это то же, что «связь» между глаголом и окончанием управляемого существительного, то есть то, чего нет и не может быть. Поэтому подобие связи, оставшееся после распада подчинения, представляется целесообразным квалифицировать как рефлекс подчинения. Учитываться в системе связей конструкции (1) этот рефлекс подчинения не должен.

Лексикализация бывших предикативных структур типа черт знает выразительно подчеркивается пунктуацией: запятая, обязательная в (3), в (1) исчезает. Результатом лексикализации оказывается обогащение репертуара средств выражения семантической категории неопределенности в русском языке. (Можно заметить, что в английском есть аналогичная конструкция God knows what. Существование близких соответствий в других славянских, а также романских и германских языках отмечено в указ. раб. Л. Л. Иомдина.) Что же касается «гипотезы о двух синтаксических началах», то ее избыточность представляется в свете изложенного очевидной.

\section{Литература}

Апресян Ю.Д., Богуславский И. М., Иомдин Л. Л., Санников В. З. Теоретические проблемы русского синтаксиса: Взаимодействие грамматики и словаря / Отв. ред. Ю. Д. Апресян. М.: Языки славянской культуры, 2010. 408 с.

Дьмарский М.Я. К типологии синтаксических связей (на материале русского языка) // Проблемы функциональной грамматики: Принцип естественной классификации / Отв. ред. А. В. Бондарко, В. В. Казаковская. ИЛИ РАН. М.: Языки славянской культуры, 2013. С. 57-91.

Дымарский М.Я. Моноцентризм в синтаксисе: эпизоды истории и современность // Structures \& functions: Studies in Russian linguistics (Структуры и функции: Исследования по русистике). Vol. II. Issue 1. Tallinn, 2015. C. 5-15.

Ильенко С.Г., Лёвина И.Н. Лексико-синтаксический словарь русского языка: Модели сложноподчиненного предложения. СПб.: Изд-во РГПУ им. А.И. Герцена, 2007. 
Сачков Ю. В. Детерминизм // Новая философская энциклопедия: В 4 т. / Ин-т философии РАН. М.: Мысль, 2010. Т. І. С. 631-632.

СинТагРус $=$ Синтаксически размеченный подкорпус Национального корпуса русского языка. Электронный ресурс: http://ruscorpora.ru/instruction-syntax.html.

\section{Mikhail Ja. Dymarskij \\ Herzen State Pedagogical University of Russia / \\ Institute for Linguistic Studies (Russian Academy of Sciences) \\ (Saint Petersburg, Russia) \\ dym2005@list.ru \\ SUBORDINATION DECAY AND LEXICALIZATION OF A PREDICATIVE STRUCTURE}

Constructions of the type (1) On zanimaetsya chert znaet chem, lit. 'He is engaged in the devil knows what' are considered in light of the "hypothesis of two syntactic beginnings" (or "heads") previously put forward by L. L. Iomdin. It is shown that such a hypothesis could appear only on the basis of the postulates used to calculate syntactic relations and model sentences in the Syntactically Marked Sub-Corpus of the National Corpus of the Russian Language (SynTagRus), but that this hypothesis contradicts these same postulates. The structure under consideration is analyzed as a result of the disintegration of subordination in the initial structure Chert znaet, chem on zanimaetsya ('The devil knows what he is engaged in'). There is no double dependence of the form of the instrumental case (from znaet 'knows' and from zanimaetsya 'engaged in') not only in the derivative, but also in the original construction, where the verb znaet subordinates not the pronoun, but the whole subordinate clause. In the derivative construction (1), we observe the result of the lexicalization of the former main part of a complex sentence, which turns into a unit similar to other former main parts with an uncertainty value (neizvestno, nevedomo 'unknown') and, just like these indicators, subordinates not the subordinate part in whole, but only what remains of it after its predicative center is moved to the left from the former main part. This degenerated link cannot be called subordination; it is only a reflex of subordination. The basis for lexicalization is that the structure chert znaet, adjoining, as in (1), the interrogative relative pronoun, expresses a unique semantic and pragmatic complex of meanings that is not available for standard indefinite pronouns: the maximum degree of uncertainty + the disapproval of the speaker. In this case, the meaning of the uncertainty, which is characteristic of the original construction, can be reduced to zero. The lexicalized structure chert znaet significantly enriches the repertoire of means of expressing the semantic category of uncertainty.

Keywords: syntax, complex subordinate sentences, syntactic links, disintegration of subordination, reflex of subordination, lexicalization, semantic category of uncertainty. 


\section{References}

Apresjan Ju. D. (ed.), Boguslavskij I.M., Iomdin L. L., Sannikov V.Z. Teoreticheskie problemy russkogo sintaksisa: Vzaimodejstvie grammatiki i slovarja [Theoretical problems of Russian syntax: The interaction of grammar and vocabulary]. Moscow: Jazyki slavjanskoj kul'tury Publ., 2010. 408 p. (in Russ.)

Dymarskij M. Ja. [Towards the typology of syntactic links (on the material of the Russian language)]. Problemy funkcional'noj grammatiki: Princip estestvennoj klassifikacii [Problems of Functional Grammar. The Natural Classification principle] Ed. by A.V. Bondarko, V.V. Kazakovskaja. Moscow, «Jazyki slavjanskoj kul'tury» Publ., 2013, pp. 57-91. (in Russ.)

Dymarskij M. Ja. [Monocentrism in syntax: episodes of history and modernity]. Structures \& functions: Studies in Russian linguistics. Vol. II. Issue 1. Tallinn, 2015, pp. 5-15. (in Russ.)

Il'enko S. G., Ljovina I.N. Leksiko-sintaksicheskij slovar' russkogo jazyka: Modeli slozhnopodchinennogo predlozhenija [Lexico-syntactic dictionary of the Russian language: Models of complex subordinate sentences]. St. Petersburg: Herzen State Pedagogical Univ. Publ., 2007. (in Russ.)

Sachkov Ju. V. [Determinsm]. Novaja filosofskaja jenciklopedija [The New Encyclopedy of Philosophy]. Moscow: Mysl' Publ., 2010, v. I, pp. 631-632. (in Russ.)

SinTagRus = Sintaksicheski razmechennyj podkorpus Nacional'nogo korpusa russkogo jazyka [Syntactically Marked Sub-Corpus of the National Corpus of the Russian Language]. Available at: http://ruscorpora.ru/instruction-syntax.html. (in Russ.) 